\title{
Enhanced universal quantification of biomolecules using element MS and generic standards: application to intact protein and phosphopro- tein determination.
}

\author{
Francisco Calderón-Celis, ${ }^{1}$ Naoki Sugiyama, ${ }^{2}$ Michiko Yamanaka, ${ }^{2}$ Tetsushi Sakai, ${ }^{2}$ Silvia Diez- \\ Fernández, ${ }^{1}$ Juan J. Calvete, ${ }^{3}$ Alfredo Sanz-Medel, ${ }^{1}$ Jorge Ruiz Encinar. ${ }^{1 *}$ \\ 1. Department of Physical and Analytical Chemistry, University of Oviedo, Julián Clavería 8, 33006 Oviedo, Spain. \\ 2. Agilent Technologies International Japan, Ltd., 9-1 Takakura-cho, Hachioji-shi, Tokyo, 192-0033, Japan. \\ 3. Instituto de Biomedicina de Valencia, IBV-CSIC, Jaume Roig 11, 46010 Valencia, Spain.
}

\begin{abstract}
Tools that provide absolute quantification of biomolecules, particularly of proteins and their post-translational modifications, without needing suitable specific standards, are urgently demanded nowadays. To this end, we have significantly improved the recently introduced strategy based on $\mathrm{CH}_{4}$ addition to the plasma for absolute quantification of biomolecules using HPLC-ICP-MS. Addition of $\mathrm{CO}_{2}$ has been optimized and finally selected as a safer, and more efficient quantitative strategy, able to provide constant $(<6 \%$ error) signal response factor for the six elements assayed ( $\mathrm{S}, \mathrm{P}, \mathrm{As}, \mathrm{Se}, \mathrm{Br}, \mathrm{I})$ under compromise conditions. In the particular case of absolute protein quantification, accuracy and precision attainable for S-based absolute determination of intact proteins using internal and external S-generic standards were compared. Potential for real sample analysis was demonstrated by the high-sensitive analysis of toxins present in snake venoms. Finally, multi-elemental speciation capabilities of the approach have been also demonstrated through $\mathrm{P}$ and $\mathrm{S}$ simultaneous analysis in phosphoproteomics. Simultaneous accurate determination of both absolute protein amount and corresponding phosphorylation degree for intact $\beta$-Casein, and even impurity traces of $\kappa$ and $\alpha$-s 1 isoforms present, have been successfully achieved using a simple mixture of inorganic $\mathrm{P}$ and $\mathrm{S}$ standards. Lowest detection limits ( $<1$ fmol protein) ever published for S- and P-based intact protein quantification with ICP-MS are reported.
\end{abstract}

Absolute quantification of low amounts of specific biomolecules is nowadays demanded in different branches of Life Sciences, such as quantitative proteomics, environmental, toxicological, pharmaceutical or food science studies. This demand is also critical in metrology, in order to provide and certificate biomolecule standards. In particular, determinations of absolute quantities of proteins are required for the understanding of the proteome dynamism, search and validation of novel protein biomarkers, stoichiometry determination within protein complexes, or determination of post-translational modifications (PTMs) levels. ${ }^{1,2}$ This absolute quantification is especially relevant in the analysis of intact proteins (top-down proteomics), ${ }^{3}$ to facilitate more direct and efficient translation of proteomics data into biologically relevant information. ${ }^{4}$

Most extended MS-based proteomics approaches make use of specific standards to carry out absolute quantifications, ${ }^{2,5}$ thus being limited by their availability and quality. In contrast, elemental mass spectrometry (ICP-MS) can provide absolute quantities using non-specific standards. ${ }^{6}$ Of course, it is clear that the key element to open the door for really generic protein quantification is sulfur, as it is present in the vast majority of eukariotic proteins. $^{7}$ The recent venue of tandem MS/MS instruments into the market, able to improve dramatically $\mathrm{S}$ detection with ICP-MS, ${ }^{8}$ has boosted this strategy tremendously. In this context, there are several reasons leading absolute protein quantification with ICP-MS to intact proteinbased approaches. First, efficiency of enzymatic digestions, responsible to break down target proteins into peptides, is far from being complete and reproducible, ${ }^{9}$ affecting negatively accuracy of quantification. Second, ICP-MS sensitivity achievable is compromised when target $\mathrm{S}$ atoms are distributed among many chromatographic peaks (peptides). Last, but not least, an average-sized eukaryotic protein, typically containing $35-50 \mathrm{~S}$ atoms, can generate tens of Scontaining peaks/peptides. This number would rise up to hundreds if targeting even simple protein mixtures. As a result, pre-ICP-MS separation required for accurate and reliable quantification of simple protein mixtures becomes impossible. Nonetheless, HPLC-ICP-MS absolute quantification of intact proteins is still far from being easy mostly because intact protein recovery from the column must be complete. Fortunately, the use of core-shell RP columns has proved to be effective for this purpose. ${ }^{10}$ In fact, absolute quantification of protein mixtures (containing up to 25 proteins) without resorting to specific standards could be recently accomplished with excellent accuracy and precision. ${ }^{11}$

Additionally, promising ICP-MS-based absolute protein quantifications require that the elemental response factor is maintained constant and/or under control along the whole chromatographic analysis necessary to separate the different element-containing species present in the sample. Unfortunately, acetonitrile-water gradients demanded in both reversed-phase and HILIC chromatographies, typically carried out for separation of biomolecules (proteins) in Life Sciences, lead to dramatic response factor variations along them. ${ }^{12}$ 
Strategies proposed so far to correct for such variations imply pre- or post-column complex instrumental set-ups, and/or use of expensive isotopically-enriched reagents. ${ }^{13-15}$ Moreover, those strategies are typically valid just for one single target element at a time. Alternatively, an approach based on the direct and controlled addition of methane gas to the ICP plasma, has been recently introduced as new and simpler tool in the search for a universal solution. ${ }^{16}$ Therein, signal variations along HPLC-ICP-MS analysis were made negligible ( $<15 \mathrm{RSD} \%$ ) for each and every of the non-metal heteroatoms of interest in life sciences ( $, \mathrm{P}, \mathrm{As}, \mathrm{Se}, \mathrm{Br}, \mathrm{I})$ under the same instrumental conditions. In addition, that universal solution provided 2- to 8-fold sensitivvity enhancemet, depending on the element. Unfortunately, compromise conditions (50 $\mathrm{mL} / \mathrm{min} \mathrm{CH}_{4}$ :Ar) found for simultaneous multielemental quantitative speciation reduce the excellent analytical features obtained for individual element analysis, especially $\mathrm{P}$ and $\mathrm{S}$ (up to $25 \%$ error).

The use of $\mathrm{CO}_{2}$ gas proposed herein constitutes a definitive step forward in this direction, as it provides much better correction of signal variations for all elements simultaneously (<6 RSD\%), while maintaining sensitivity enhancement (2 - 9 fold). The use of carbon dioxide instead of methane, which is inflammable, also brings lower security concerns. The superior performance of this methodology has been evaluated for the quantification of intact proteins in standards and real samples through the ICP-MS detection of sulfur. Finally, its capacity to provide much better correction for all the elements simultaneously has been demonstrated by the straightforward and accurate determination of the protein content and phosphorylation degree of both major and low-abundant phosphoproteins present in a sample using a simple mixture of sulfur and phosphorus inorganic standards.

\section{EXPERIMENTAL SECTION}

\section{Reagents and materials.}

Phosphorous, sulfur, bromine, selenium, iodine, and arsenic ICP standards $(1000 \mathrm{mg} / \mathrm{L})$ were purchased from SPEX CertiPrep, Inc (New Jersey, USA). BOC-L-Methionine, Bis(4nitrophenyl) phosphate (BNPP), bovine serum albumin (BSA), human transferrin, and bovine $\beta$-casein were purchased from Sigma-Aldrich (Steinheim, Germany). All solutions were prepared in ultrapure MilliQ water, obtained from Millipore SAS system, with $0.22 \mu \mathrm{m}$ filter (Molsheim, France). Mobile phase B was prepared in Acetonitrile (ACN) Optima LC/MS, purchased from Wako Pure Chemical Industries, Ltd (Osaka, Japan). Formic acid used in both mobile phases as ion pairing $(0.2 \%(\mathrm{v} / \mathrm{v}))$ was purchased from Wako Pure Chemical Industries, Ltd (Osaka, Japan).

\section{Instrumentation.}

capHPLC system was an Agilent Infinite Capillary HPLC 1260 Series (Agilent Technologies, Waldbronn, Germany), with column heating and autosampler modules. The reversed phase capHPLC column used was Sigma BIOShellTM A400 C4, $3.4 \mathrm{um}, 150 \mathrm{~mm} \times 0.3 \mathrm{~mm}$ (Sigma-Aldrich, Steinheim, Germany). ICP-MS system consisted on a Triple Quad ICPMS, ICP-MS(QQQ) (Agilent 8900, Tokyo, Japan). A total consumption nebulizer (Capillary LC interface, Agilent) was used as interface between the capHPLC and the ICP systems.

Methane $\left(\mathrm{CH}_{4}: \mathrm{Ar}, 10: 90\right)$ and carbon dioxide $\left(\mathrm{CO}_{2}: \mathrm{Ar}\right.$, 10:90) gas mixtures (Takachiho Chemical Industrial, Tokyo,
Japan) introduction to the plasma was controlled by Mass Flow Controller 5100 N030 KOFLOC (Kyoto, Japan). $\mathrm{CO}_{2} / \mathrm{CH}_{4}$ :Ar was mixed on-line with the optional gas $\mathrm{O}_{2}$ : $\mathrm{Ar}$ (20:80) (Takachiho Chemical Industrial, Tokyo, Japan) through a T-connection 5/32" (John Guest, Middlesex, UK), located between the exit of the optional gas from the ICP-MS and the optional inlet of the nebulization chamber.

\section{Procedures.}

Controlled addition of $\mathrm{CO}_{2} / \mathrm{CH}_{4}:$ Ar gases to evaluate the correction of elemental signal variations along chromatographic gradients.

capHPLC-ICP-MS/MS signals of P, S, As, Se, Br, and I were recorded along reversed-phase gradients $(0-70 \% \mathrm{~B}$ in $35 \mathrm{~min}$ ), when adding different $\mathrm{CO}_{2} / \mathrm{CH}_{4}$ : Ar flows to the plasma, ranging from 0 to $100 \mathrm{~mL} / \mathrm{min}(10 \mathrm{~mL} / \mathrm{min}$ steps $)$. Both chromatographic mobile phases $\mathrm{A}\left(\mathrm{H}_{2} \mathrm{O} /\right.$ formic acid) and B (ACN/formic acid) were spiked with $300 \mu \mathrm{g} / \mathrm{L}$ of each assayed elements. Carrier gas flow (Ar) was $0.85 \mathrm{~L} / \mathrm{min}$, and optional gas flow $\left(\mathrm{O}_{2}\right.$ :Ar) was 6\%. MS/MS mode was operated with $\mathrm{O}_{2}$ as reaction gas at $25 \%$. P, S, Se, and As were measured in mass shift mode, whilst $\mathrm{Br}$, and $\mathrm{I}$, in the on mass mode. Chromatographic flow of $3.5 \mu \mathrm{L} / \mathrm{min}$ was used as it is perfectly compatible to the total consumption nebulizer used. ${ }^{17}$

\section{Protein and phosphoprotein quantitative analysis.}

Protein samples were spiked with the corresponding internal standard (IS) and analyzed by capHPLC-ICP-MS/MS. Protein and standards concentration ranged between $100-200 \mu \mathrm{g} / \mathrm{mL}$. Chromatographic conditions were: $3.5 \mu \mathrm{L} / \mathrm{min} ; 2-70 \% \mathrm{~B}$ in $35 \mathrm{~min}$, and injection volume was $1 \mu \mathrm{L}$. To carry out external calibration, $1 \mu \mathrm{L}$ of quantification standards was injected (quadruplicate) via flow injection analysis (FIA) before the chromatographic analysis. capFIA conditions were the same as those at the starting point of the chromatographic analysis.

\section{Analysis of Pseudechis papuanus venom.}

Sample preparation and analysis was carried out following previosly described protocol. ${ }^{11}$ Briefly, reconstituted venom samples were analyzed with capHPLC-ICP-MS/MS after capFIA analysis of the $S$ standard. Venom proteins were separated by reversed-phase capHPLC. $1 \mu \mathrm{L}$ of sample was chosen as sample injection volume and column flow rate was set at $4.5 \mu \mathrm{L} / \mathrm{min}$. Gradient used was: $1.5 \%$ B for $5 \mathrm{~min}, 1.5-$ $10 \% \mathrm{~B}$ in $8 \mathrm{~min}, 10-30 \% \mathrm{~B}$ in $67 \mathrm{~min}$, and $30-90 \% \mathrm{~B}$ in 7 min. Optimized $\mathrm{CH}_{4}$ :Ar and $\mathrm{CO}_{2}$ :Ar flows were added to the plasma during the analyses

\section{RESULTS AND DISCUSSIONS}

Critical comparison between $\mathrm{CO}_{2}: \mathrm{Ar}$ and $\mathrm{CH}_{4}: \mathrm{Ar}$ to correct signal variations during capHPLC-ICP-MS/MS analyses.

Most recently, we reported the "proof of concept" for an efficient universal correction of element signal variations during separations of biomolecules along chromatographic gradients involving organic modifiers (e.g., ACN), using direct addition of the mixture of $\mathrm{CH}_{4}: \mathrm{Ar}$ to the ICP-MS. ${ }^{16}$ Simultaneous quantitative speciation analysis of up to six biologically interesting elements (S, P, Se, As, Br, I) was accomplished with that simple solution, without the need to resort to any specific standard or isotopic tracer. Here, we have evaluated $\mathrm{CO}_{2}: \mathrm{Ar}$ as a safer and most advantageous alternative to $\mathrm{CH}_{4}: \mathrm{Ar}$. 


\section{$\mathrm{CO}_{2}: \mathrm{Ar}$}
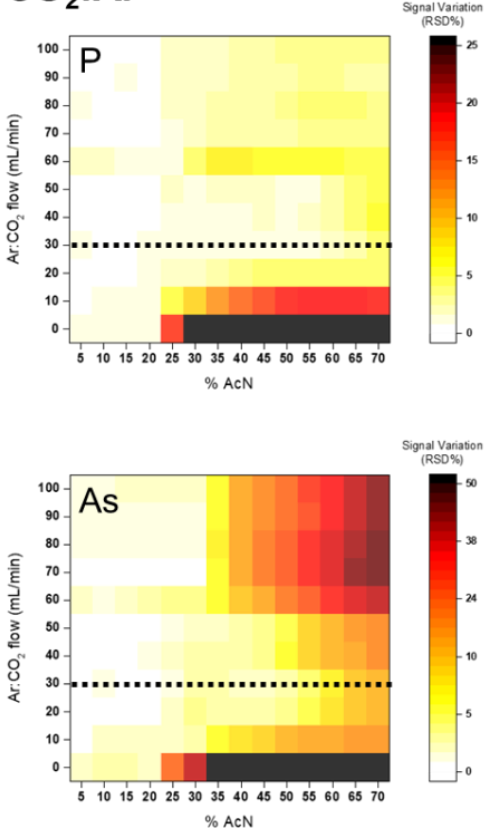

\section{$\mathrm{CH}_{4}: \mathrm{Ar}$}
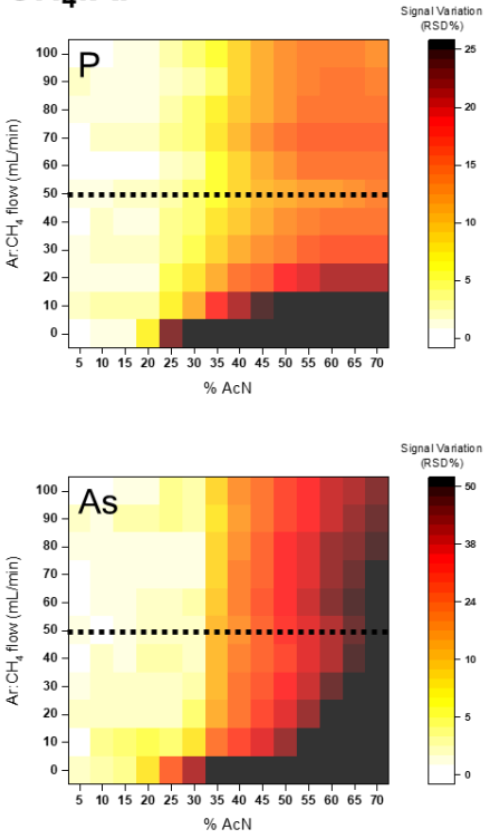
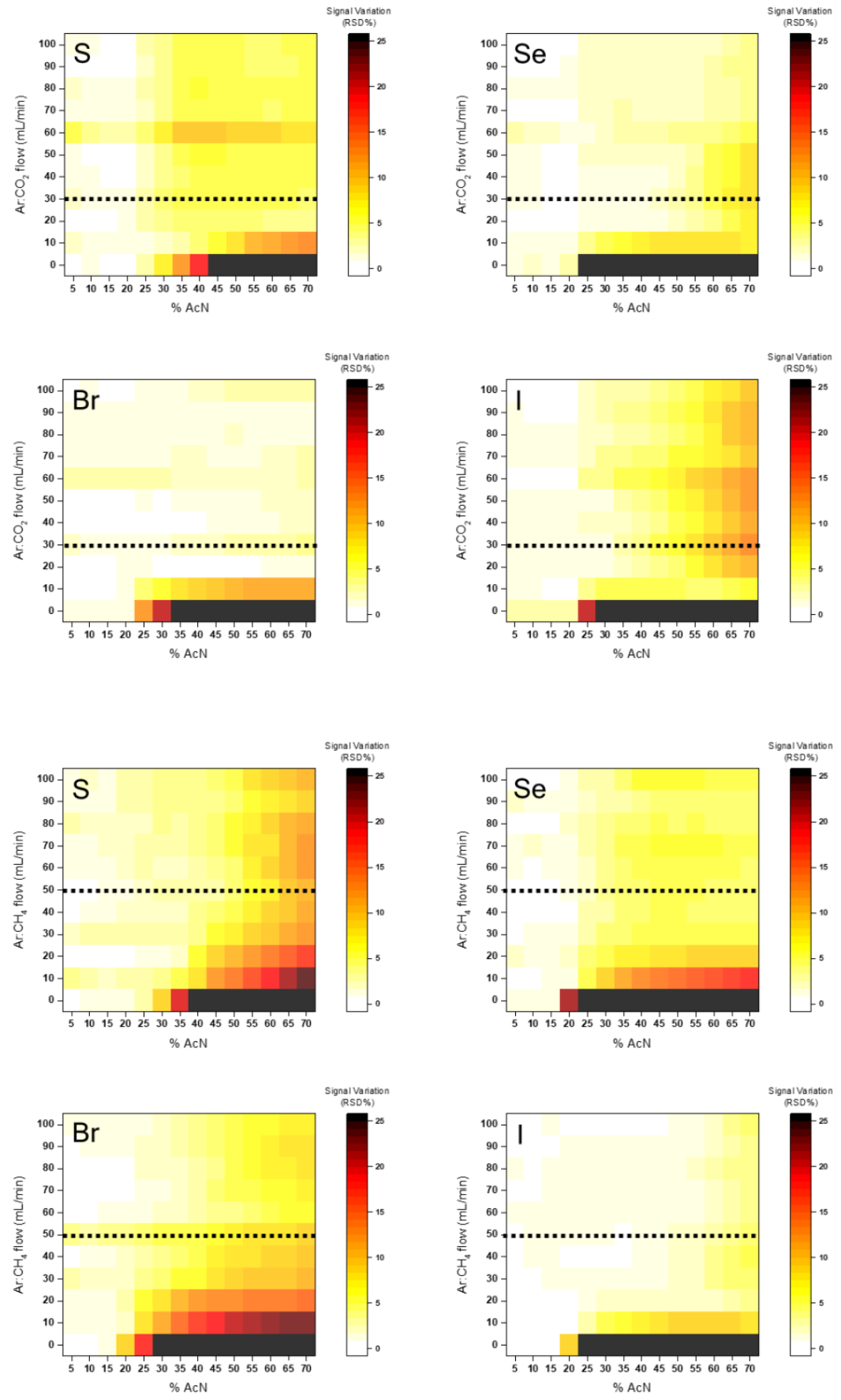

Figure 1. Heat maps representing signal variations along capHPLC-ICP-MS/MS gradients for P, S, As, Se, Br, and I, given as the accumulated relative standard deviation $(\mathrm{RSD} \%)$ of the signal at every moment of the analysis $(\% \mathrm{ACN})$, under each of the $\mathrm{CO}_{2}$ :Ar (up) and $\mathrm{CH}_{4}: \mathrm{Ar}$ (down) flows assayed. Dotted lines indicate compromise optimal gas flows found for multi-elemental analysis.

Target elements were spiked to both mobile phases at the same concentration so that constant signal could be expected along the gradient if sensitivity changes due to the acetonitrile do not exist or are corrected for. Elemental signals were monitored along gradients with controlled and continuous addition of $\mathrm{CH}_{4}$ :Ar or $\mathrm{CO}_{2}$ :Ar. Flow range evaluated was kept between 0 and $100 \mathrm{~mL} / \mathrm{min}$, in sight that optimal previous "compromise" conditions had been found around $50 \mathrm{~mL} / \mathrm{min}$ $\mathrm{CH}_{4}$ :Ar. ${ }^{16}$ Changes in sensitivity along the analysis $(0-50 \%$ $\mathrm{ACN}$ ), were represented in terms of accumulated relative standard deviation (RSD\%) of the recorded elemental signals (see Figure 1). Therefore, the lower the RSD\% value, the more constant the signal response factor during the analysis. Most biomolecules analyzed by HPLC-ICP-MS elute with ACN concentrations lower than $50 \%$ and therefore, data treatment was focused within that working range. Nevertheless, our study was done until $70 \% \mathrm{ACN}$, just in order to cover completely typical gradient ranges in RP-LC and HILIC analyses.

$\mathrm{CH}_{4}$ :Ar heat maps profiles herein obtained for all the elements assayed using a second generation ICP-MS(QQQ) 
instrument (Agilent 8900), were very similar to those reported using a first generation ICP-MS(QQQ) instrument (Agilent 8800). ${ }^{16}$ Considering that both studies have been carried out in different laboratories, and with different HPLC-ICP-MS instrumentation, such results equivalence for most elements assayed seems to demonstrate robustness, and reproducibility of the whole approach.

\section{5}
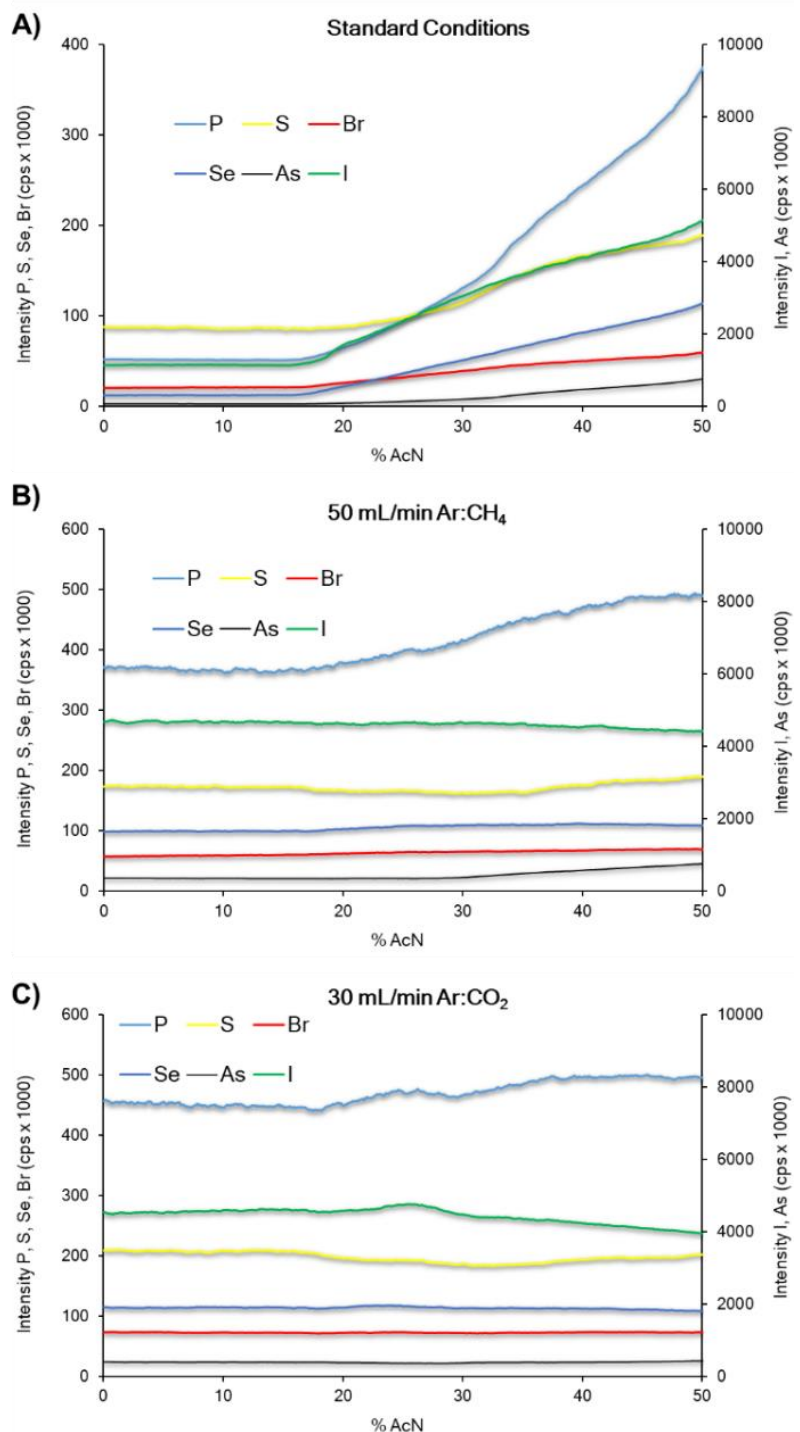

Figure 2. capHPLC-ICP-MS/MS chromatograms obtained for $\mathrm{P}, \mathrm{S}, \mathrm{Br}, \mathrm{Se}, \mathrm{As}$, and I, under (A) standard conditions, and the addition of (B) $50 \mathrm{~mL} / \mathrm{min} \mathrm{CH}_{4}: \mathrm{Ar}$ and (C) $30 \mathrm{~mL} / \mathrm{min}$ $\mathrm{CO}_{2}$ :Ar.

$\mathrm{CH}_{4}$ :Ar and $\mathrm{CO}_{2}$ :Ar heat maps in Figure 1 clearly show that signal variations are significantly reduced using both $\mathrm{CO}_{2}$ : $\mathrm{Ar}$ or $\mathrm{CH}_{4}$ :Ar gases as compared to standard conditions (when no gas was added, bottom line in heat maps). In the case of $\mathrm{CO}_{2}$ :Ar, lower accumulated $\mathrm{RSD} \%$ was observed in comparison to $\mathrm{CH}_{4}$ :Ar. Additionally, the regions of flow ranges with stable correction of signal variations were much wider.

Potential quantitative errors were computed as the difference $(\%)$ between elemental response factor obtained at the beginning of the gradient (where both generic internal spiked and external standards injected are detected) and at 50 $\%$ ACN (where most of the biomolecules, such as proteins, are typically detected), and are summarized in Tables S1 and S2. These results corroborate the individual trends observed in the heat maps in Figure 1 and chromatograms in Figure 2. In the case of $\mathrm{CH}_{4}: \mathrm{Ar}$, quantitative errors for $\mathrm{S}, \mathrm{Se}, \mathrm{Br}$, and I were kept $\leq 10 \%$ in most flows assayed, in contrast to the $55-340$ $\%$ error obtained using standard conditions. In the case of $\mathrm{P}$, quantitative errors were $<15 \%$ for most $\mathrm{CH}_{4}$ :Ar flows, whereas for As, observed quantitative errors were in the range of $20-30 \%$, still decreasing over 10 times respect to standard conditions. It is worth remarking that our previous study proved that optimum signal corrections in the analyses of $\mathrm{P}$ and As would require much higher flows (200 - 250 $\mathrm{mL} / \mathrm{min}) .{ }^{16}$ As a matter of fact, compromise conditions found for multi-elemental quantitative speciation $(50 \mathrm{~mL} / \mathrm{min})$ were far from the optimim correction observed for $\mathrm{P}$ and As. However, addition of those high flows implied lower sensitivity for all elements. Moreover, security concerns are also higher. On the contrary, the addition of $\mathrm{CO}_{2}$ : $\mathrm{Ar}$ proposed here provided complete signal variations correction, so that quantitative errors under certain flow ranges were below $6 \%$ for each and every element. In fact, compromise conditions (combination of lower quantitative error with higher sensitivity enhancement for all elements) found at $30 \mathrm{~mL} / \mathrm{min}$ $\mathrm{CO}_{2}$ :Ar were indeed optimal for the six elements facilitating simultaneous multi-element speciations.

Summarising, correction of signal variations with the proposed approach has been demostrated with both gas mixtures evaluated, and optimal conditions for speciation analysis have been found for each element. However, for multi-elemental speciation, signal variations correction is much superior using $\mathrm{CO}_{2}: \mathrm{Ar}(30 \mathrm{~mL} / \mathrm{min})$ instead of $\mathrm{CH}_{4}: \mathrm{Ar}$ $(50 \mathrm{~mL} / \mathrm{min})$ flow, as clearly shown in Figure $2 \mathrm{~B}$ and $2 \mathrm{C}$. It is evident from Figure $2 \mathrm{C}$ that element signal for all target elements is perfectly constant along the gradient $(0-50 \%$ $\mathrm{ACN}$ ), opening the door for the simultaneous quantification of any biomolecule containing any of the elements under study with the corresponding element-containing generic and simple standards.

Comparison of element signal at each moment of the analysis, under the addition of $\mathrm{CO}_{2}$ : $\mathrm{Ar}$ or $\mathrm{CH}_{4}$ : $\mathrm{Ar}$, with respect to standard conditions, provided information on signal enhancement or depletion when adding the gas. In Figure S1, a 2- to 9-fold increased sensitivity with $\mathrm{CH}_{4} / \mathrm{CO}_{2}$ :Ar addition was observed respect to standard conditions, depending on the element. Interestingly, maximum enhancement in the case of $\mathrm{CO}_{2}$ : Ar was observed in a narrower flow range (10 - 50 $\mathrm{mL} / \mathrm{min})$ than for $\mathrm{CH}_{4}: \mathrm{Ar}(10-80 \mathrm{~mL} / \mathrm{min})$. In both cases, this sensitivity enhancement caused by the carbon effect, ${ }^{18,19}$ was comparable to that obtained in our previous work with $\mathrm{CH}_{4}: \mathrm{Ar},{ }^{16}$ and observed by other authors, especially in Se speciation studies. ${ }^{19,20}$

Comparison of strategies for sensitive sulfur-based abolute quantification of intact proteins.

Two model protein standards, BSA and transferrin, were simultaneously quantified via capHPLC-ICP-MS/MS analysis through the detection of their constituent sulfur. Optimal flow of $30 \mathrm{~mL} / \mathrm{min} \mathrm{CO}_{2}$ :Ar was used to correct signal variations along the chromatographic gradient. Two quantification approaches were critically evaluated, internal and external standardization, using the same quantification standard, BOC- 
L-methionine. In the first case, BOC-L-methionine was spiked to the protein sample, whereas external standardization consisted on the injections, via capFIA $(n=4)$, of the BOC-Lmethionine, prior to the chromatographic analysis of the sample (see Figure 3). In both cases, quantitative data was extracted from the sulfur response factor obtained from the generic standard. Sulfur concentration for each intact protein peak could be then translated into protein concentration since amino acid sequences of standards were known.

Table 1. Theoretical, certified (via post-column IDA), and experimental values (individual replicates on the left, and average value on the right) obtained for BSA and transferrin mass purity certification, using $\mathrm{CO}_{2}$ :Ar with internal and external standardization.

\begin{tabular}{|c|c|c|c|c|}
\hline & \multicolumn{2}{|c|}{ BSA } & \multicolumn{2}{|c|}{ Transferrin } \\
\hline Theoretical value & \multicolumn{2}{|c|}{$\geq 98$} & \multicolumn{2}{|c|}{$\geq 95$} \\
\hline $\begin{array}{c}\text { Post-column } \\
{ }^{34} \text { S IDA (Ref. }{ }^{10} \text { ) }\end{array}$ & \multicolumn{2}{|c|}{$96 \pm 2$} & \multicolumn{2}{|c|}{$94 \pm 2$} \\
\hline \multirow{3}{*}{$\begin{array}{c}\mathrm{CO}_{2}: \mathrm{Ar} \text { with } \\
\text { internal standard }\end{array}$} & 97 & \multirow{3}{*}{$99 \pm 2$} & 96 & \multirow{3}{*}{$95 \pm 1$} \\
\hline & 99 & & 95 & \\
\hline & 100 & & 94 & \\
\hline \multirow{3}{*}{$\begin{array}{c}\mathrm{CO}_{2} \text { :Ar with } \\
\text { external standard }\end{array}$} & $94 \pm 2$ & \multirow{3}{*}{$97 \pm 3$} & $94 \pm 4$ & \multirow{3}{*}{$93 \pm 3$} \\
\hline & $96 \pm 3$ & & $90 \pm 2$ & \\
\hline & $99 \pm 3$ & & $94 \pm 3$ & \\
\hline
\end{tabular}

BSA and transferrin proteins had been previously certified with IDA, through the post-column continuous addition of a solution enriched in ${ }^{34} \mathrm{~S}$ to the chromatographic stream. ${ }^{10}$ Therefore, those results could be used for validation purposes. Protein mass purities obtained from the quantitative results of the mixture for BSA and transferrin and internal standard were $99 \pm 2 \%$, and $95 \pm 1 \%$, respectively. Individual triplicate results are given in Table 1 . These results are in excellent agreement with both the values given by the manifacturer (theoretical) and those obtained with IDA as reference method. Results obtained with external calibration are accurate as well, as shown in Table 1. Of course, as element response factor is obtained in this case from a cuatriplicate injection, every individual analysis comes with associated uncertainty. Therefore more reliable combined uncertainty for the final sample triplicate injection could be obtained. Surprisingly, such combined uncertainty ( $3 \%$ RSD) is not significantly higher than uncertainty from internal standardization $(\sim 1-2$ $\%$ RSD). Therefore, we would recommend always this option, since internal calibration requires to check that internal standard added does not co-elute with any S-containing species originally present in the sample.

As mentioned before, it is strictly necessary to achieve complete protein recovery from the chromatographic column in order to obtain accurate results in ICP-MS-based generic absolute protein quantification. As shown in Figure 3, this requisite can be easily assesed by injecting the protein sample via FIA prior to the chromatographic analysis and computing the sulfur area ratio between the sum of all the chromatographic peaks and the global FIA peak. Of course, this straightforward way of computing protein column recovery requires again for sensitivity constant along chromatographic gradients. In this work, recovery for the protein mixture analyzed was $100 \pm 4 \%(n=3)$. Therefore, Figure 3 can be taken as a clear example of the quantitative approach proposed. First, blanks, sample recovery from the column and external calibration can be easily performed using capFIA and then, chromatographic analysis of the target sample can be done. The complete analysis time prior to the chromatographic analysis should be no longer than $40 \mathrm{~min}$.

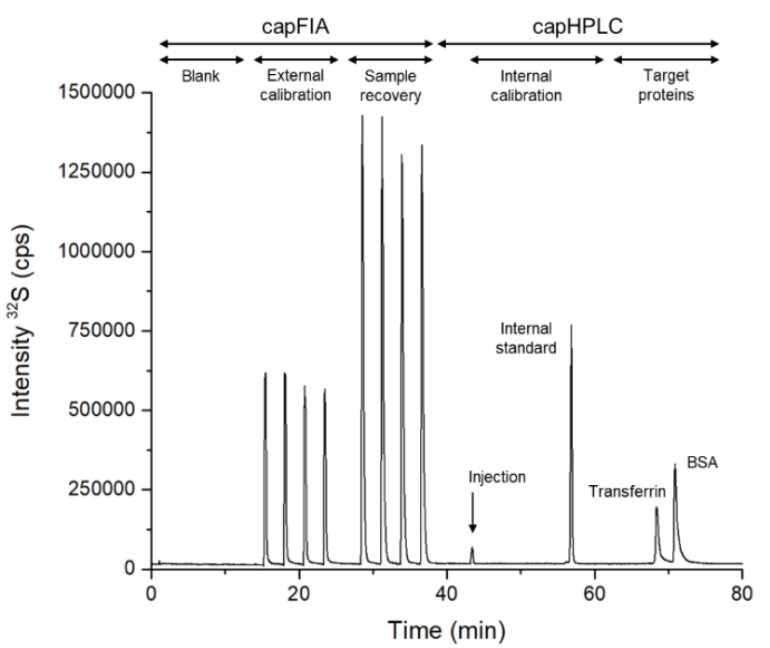

Figure 3. capFIA-HPLC-ICP-MS/MS of transferrin and BSA, using BOC-L-Met as (internal and external) quantification standard and $30 \mathrm{~mL} / \mathrm{min} \mathrm{CO}_{2}: \mathrm{Ar}$.

In our previous work, applicability of the addition of $\mathrm{CH}_{4}$ :Ar to the plasma for the S-based quantification of proteins in real samples was demonstrated and validated with Isotope Dilution Analysis. ${ }^{16}$ Herein, we have likewise demonstrated the suitability of $\mathrm{CO}_{2}$ :Ar for such analysis. To do so, capHPLC-ICP-MS/MS quantitative analysis of Pseudechis papuanus venom sample was carried out with both $\mathrm{CO}_{2}$ :Ar and $\mathrm{CH}_{4}: \mathrm{Ar}$ (Figure 4).

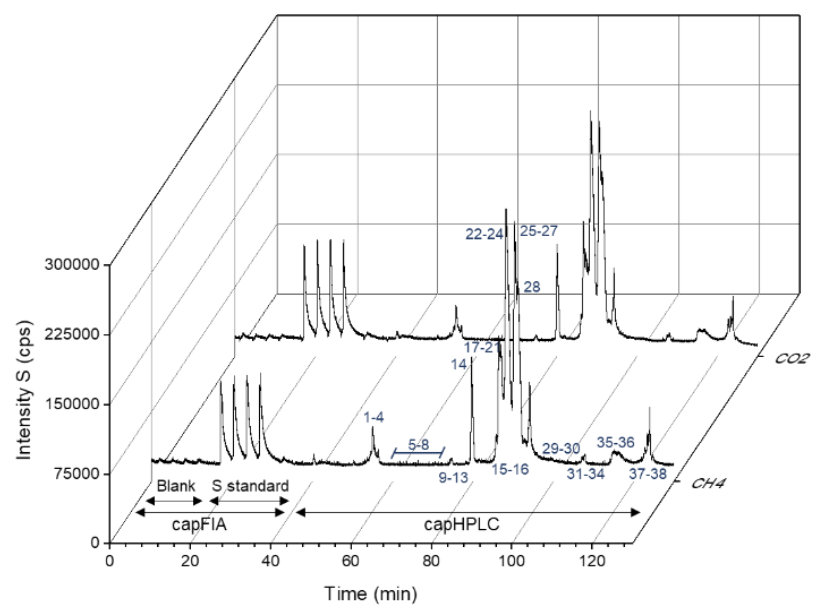

Figure 4. capFIA-HPLC-ICP-MS/MS analysis of Pseudechis papuanus using $\mathrm{CH}_{4}$ :Ar and $\mathrm{CO}_{2}$ :Ar. Previously identified proteic species ${ }^{11}$ are numbered from 1 to 38 .

Results obtained with both approaches were undistinguisable (Figure S2). The use of C-containing gases resulted in more than two-fold $\mathrm{S} / \mathrm{N}$ enhancement with respect to IDA. ${ }^{11}$ Moreover, since the liquid post-column flow used in IDA was not require anymore, chromatographic efficiency 
(number of theoretical plates) increased $60 \%$ using $\mathrm{CO}_{2}$ :Ar or $\mathrm{CH}_{4}$ :Ar, which resulted in better peak resolution and hence protein species separation.

Finally, it is worth mentioning that the lack of any extra flow of isotopically enriched ${ }^{34} \mathrm{~S}$ (as required in IDA approaches), together with the excellent sensitivity provided by the use of the $\mathrm{CO}_{2}$ :Ar gas addition mentioned before, resulted in extremely high sensitivity for ICP-MS/MS sulfur detection. In fact, LOD obtained for intact proteins was, to the best of out knowledge, the lowest ever published, ${ }^{10,21-23}$ in the range of $0.6 \mathrm{fmol}$ protein. This is much lower than those previously obtained with IDA also for intact proteins (280 590 fmol protein), ${ }^{10}$ and even lower than LOD obtained for peptides, using organic sheath flows to correct signal variations (11 fmol peptide) ${ }^{8}$

\section{Accurate direct determination of phosphorylation degree of intact proteins.}

Protein phosphorylation is one of the most preponderant and well-studied modifications. ${ }^{24,25}$ It is a reversible and dynamic process that consists on the addition and removal of a phosphate group in serine, theronine, or tyrosine residues. ${ }^{24,26}$ Phorphorylation modulates protein-protein interactions, affects protein conformations, and can control protein function in almost every cellular process. ${ }^{27}$ As a result, variations in global phosphorylation degree can cause or be related to the occurrence of diseases. ${ }^{24}$ Continuous advances and developments in molecular mass spectrometry for proteomics have rendered $\mathrm{MS}$ as a valuable tool in current phosphoproteomics, because it can provide quantitative and site-specific information on the phosphorylation when bottomup approaches are used. ${ }^{28}$ However, there is still a lack of reliable, simple, and general methods to characterize and quantify phosphoproteins, directly at the protein level. ${ }^{29}$

When using ICP-MS, knowledge of the stoichiometry element:biomolecule is required in order to translate element absolute quantity into biomolecule absolute quantity. Such stoichiometry is known for sulfur from the protein amino acid sequence because its presence is genetically encoded in cysteine and methionine amino acids. However, in the case of elements present in the biomolecule as result of posttranslational modifications, as it is the case of phosphorylation (P), this information is not known. It is therefore necessary to experimentally determine the phosphorous $(\mathrm{P})$ :protein $(\mathrm{S})$ stoichiometry.

Therefore, the proposed approach has been herein tested for such quantitative phosphoproteomics studies, using intact $\beta$ casein as model protein. Absolute concentration (mass purity) of $\beta$-casein was calculated first through sulfur detection, likewise to previous section. Meanwhile, determination of the number of phosphorous atoms present in $\beta$-casein molecule was calculated from experimental P/S peak area ratio obtained in the corresponding chromatographic peak. External (with inorganic standards via FIA) and internal calibration (BOC-LMet for S, and BNPP for P) were again compared both for $\mathrm{S}$ and $\mathrm{P}$ analysis (Figure 5). In this case, inorganic standards were tested as external calibrants in order to make the approach even simpler and easier. Regarding phosphorylation, $\mathrm{P} / \mathrm{S}$ molar ratio was obtained by relating $\mathrm{P} / \mathrm{S}$ area ratio computed in the $\beta$-casein chromatographic peak with that obtained in the generic $\mathrm{S}$ and $\mathrm{P}$ standards. Results obtained with external and internal standards were again statistically undistinguishable, and provided a value of 4.6 $\mathrm{P}$ atoms / $\beta$ casein molecule (see Table 2). This value translates into a phosphorylation degree of $92 \%$, given that the maximum number of phosphorylated sites in the amino acid sequence of the protein is five, ${ }^{30}$ which is within the expected range (80 $100 \%$ ). Notably, in this sort of determination, which relates $\mathrm{P} / \mathrm{S}$ ratios in both standard and protein peaks, any error due to the injection or incomplete chromatographic recovery does not affect the accuracy or precision of the results.

$\beta$-casein mass purities values of $94 \pm 5 \%$ and $93 \pm 6 \%$ were obtained with external and internal calibration, recpectively. Again, results with both standardization approaches are statistically undistinguisable and show similar precision. In fact, precision was slightly better with external calibration, which might be attributable to the excellent internal precision of the quadruplicate capFIA of the inorganic S standard ( 1\% RSD).

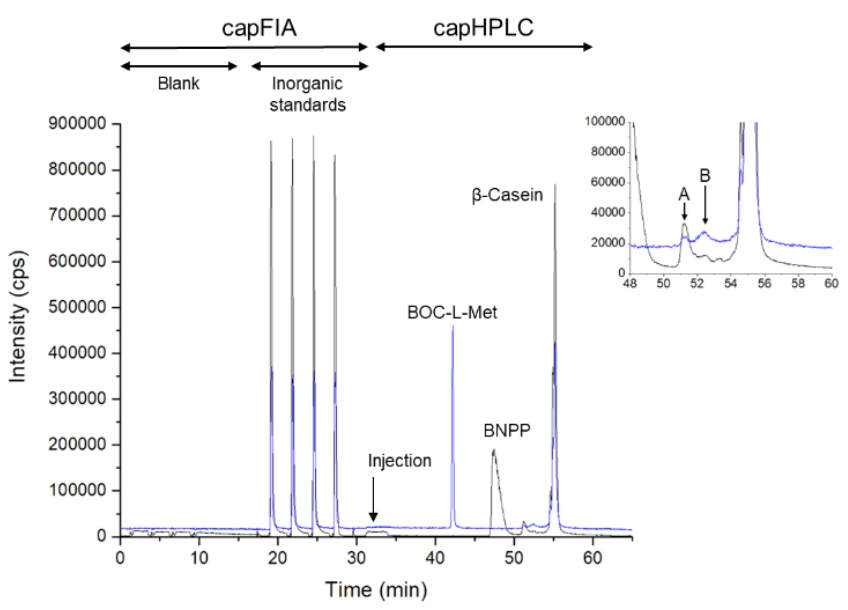

Figure 5. Phosphorous (black) and sulfur (blue) capFIAHPLC-ICP-MS/MS analysis of $\beta$-casein using BOC-L-Met (S) and BNPP (P) as internal quantification standards, and $\mathrm{S}$ and $\mathrm{P}$ inorganic standards for external calibration, and $30 \mathrm{~mL} / \mathrm{min}$ $\mathrm{CO}_{2}$ :Ar. Minor phosphorous peaks (A-B) can be observed in the inset, which likely correspond to $\alpha-S 1-, \kappa$-casein isoforms, respectively.

$\beta$-Casein phosphorylation degree value herein determined was equivalent to previous ones obtained with alternative ICPMS-based strategies ${ }^{31,32}$ but being the approach significantly simpler and more sensitive. Wind et al. proposed a strategy for the determination of P/S ratios in phosphopeptides in HPLCICP-MS analysis. ${ }^{31}$ To solve the issue of signal variations during the gradient, they determined the response factor of Sand P-containing compounds as a function of the organic solvent composition, so that they mathematically corrected the recorded signal considering the mobile phase composition at the elution time of the compounds. Of course, such correction was not accurate if signal drift affected $\mathrm{P}$ or $\mathrm{S}$ in a different way. 
Table 2. Theoretical and experimental values of $\beta$-casein concentration ( $\%$ mass purity), and phosphorylation degree obtained with external and internal calibration*. Additionally, P/S molar ratios obtained in peaks $A$ and B in inset of Figure 5 are compared with theoretical values of $\alpha$-s1-Casein, and $\kappa$-Casein, respectively.

\begin{tabular}{|c|c|c|c|}
\hline & Theoretical value & External calibration & Internal calibration \\
\hline Concentration (mass purity) & $\geq 75 \%(98 \%$ protein purity) & $94 \pm 5 \%$ & $93 \pm 6 \%$ \\
\hline P / $\beta$-Casein molar ratio & $4-5$ & $4.6 \pm 0.1$ & $4.6 \pm 0.2$ \\
\hline Phosphorylation degree & $80-100 \%$ & $92 \pm 3 \%$ & $92 \pm 3 \%$ \\
\hline P/S molar ratio peak A $(\alpha-$ s 1-Casein) & $1.3-1.7$ & $1.6 \pm 0.1$ & $1.7 \pm 0.2$ \\
\hline P/S molar ratio peak B ( $\kappa$-Casein) & 0.25 & $0.29 \pm 0.03$ & $0.30 \pm 0.03$ \\
\hline
\end{tabular}

*Uncertainty corresponds to one standard deviation $(\mathrm{n}=3)$.

Alternatively, Pereira et al. determined $\beta$-casein phosphorylation degree $(4.57 \pm 0.05 \mathrm{P}$ atoms / protein $)$ in the tryptic digest using BNPP as internal standard. However, this strategy required to know the mass of phosphorous and protein, ${ }^{32}$ and made use of an organic make-up flow to buffer changes in elemental response factor during the chromatographic gradient. More recently, Profrock et al. made use of a complex reversed gradient sheath flow (using a second HPLC pump) for the determination of $\beta$-casein phosphorylation degree $(4.60 \pm 0.28 \mathrm{P}$ atoms / protein $)$ from its tryptic digest via HPLC-ICP-MS. ${ }^{23}$ In contrast, in our approach, all these different corrections are not longer required to keep elemental response factor constant along the whole analysis. Therefore, associated limitations such as constraint chromatographic operationality, lack of robustness, complex instrumentation, element-specificiy, and/or limited working range are fully overcome.

Again, LOD obtained for $\beta$-casein via phophorous determination was the lowest so far, $0.7 \mathrm{fmol}$ of intact protein (3.4 fmol P); even lower than LODs previously obtained for the determination of phosphopeptides with ICP-MS/MS (6.6 fmol P/peptide). ${ }^{8}$ Such high sensitivity resulted in the detection of 2 very minor P-peaks that eluted before $\beta$-casein (peaks A - B, in inset of Figure 5). Parallel analysis of the protein solution by LC-MS/MS confirmed the presence of several phosphorylated species in the sample (see S.I.). Interestingly, in spite of their low concentration level, P/S molar ratio could be computed for peaks $\mathrm{A}$ and $\mathrm{B}$, which corresponded very well with $\mathrm{P} / \mathrm{S}$ molar ratios given by manufaturer for $\alpha$-s 1 - and $\kappa$-casein, respectively (see Table 2). This situation is similar to that expected in the analysis of many biological samples, in which proteins are in different concentration levels and oftenly highly-abundant proteins hinder detection of low-abundant ones (especially phosphoproteins), so that depletion, enrichment or isolation procedures are required. ${ }^{33}$ Nevertheless, in this case, direct quantitative characterization of these intact phosphorylated proteins present at trace levels has been possible without resorting to any extra enrichment procedure.

\section{CONCLUSIONS}

This works implies the analytical confirmation of the recently introduced approach, based on the addition of carboncontaining gases directly to the plasma, as a remarkable breakthrough in absolute quantitative speciation without specific standards via HPLC-ICP-MS. The herein introduction of $\mathrm{CO}_{2}$ instead of $\mathrm{CH}_{4}$ has led to a marked improvement in the analytical performance of the approach. The use of external standards has provided absolute quantification as precise and accurate as when using internal standards. However, such external standardization is simpler, and can be carried out using pure, inorganic standards.

Simultaneous quantitative multi-elemental speciation with excellent accuracy and unsurpased sensitivity has been succesfully demonstrated herein for intact phospho-protein quantification using simple inorganic $\mathrm{S}$ and $\mathrm{P}$ standards. The universal approach proposed can be likewise applied to the quantitative characterization of other modified proteins containing or bindign non-metallic elements, like Se, ${ }^{34} \mathrm{I},{ }^{35}$ or As. ${ }^{36}$ Because it is possible to carry out the analysis of those elements together with $\mathrm{S}$, stoichiometries element:protein could be accomplished directly in a single analysis from the elemental peak area ratios, without any extra correction and using simple and certified inorganic standards.

In summary, the proposed approach comprising the direct addition of $\mathrm{CO}_{2}$ :Ar to the plasma and FIA of the original sample and inorganic standards for column recovery and elements response factor computation, respectively, means to be established as workhorse in quantitative speciation and intact protein analysis using HPLC-ICP-MS. In this context, proteomics trends are heading towards the analysis of intact proteins (top-down) given the more complete biological information these approaches provide with regards to analysis of tryptic peptides. ${ }^{4}$ However, protein quantification via molecular MS-based top-down workflows is severly constrained by availability and characterization of proper specific protein standards. Consequently, the proposed approach turns up as a an excellent and robust quantitative complement for the generic certification of such intact protein standards. Moreover, its potential applicability in relatively complex real samples (i.e. snake venoms) has been also demonstrated. Last but not least, its instrumental simplicity makes this approach easily compatible with HPLC-ESI-MS strategies. Therefore, its progressive integration into established proteomics and metabolomics workflows is expected in the near future.

\section{ASSOCIATED CONTENT}

\section{Supporting Information}

The Supporting Information is available free of charge on the ACS Publications website.

Analysis of results on the correction of signal variations and signal enhancement for $\mathrm{S}, \mathrm{P}, \mathrm{As}, \mathrm{Se}, \mathrm{Br}$, 
and I, under the addition of $\mathrm{CH}_{4}: \mathrm{Ar}$ and $\mathrm{CO}_{2}$ :Ar. LCMS/MS analysis of tryptic digestion of $\beta$-casein sample. capHPLC-ICP-MS/MS quantification of Pseudechis papuanus venom sample using $\mathrm{CH}_{4}: \mathrm{Ar}$ and $\mathrm{CO}_{2}$ :Ar.

\section{AUTHOR INFORMATION}

\section{Corresponding Author}

* Corresponding author. Email: ruizjorge@uniovi.es. Telephone: +34 985103069 .

\section{Notes}

The authors declare no competing financial interest.

\section{ACKNOWLEDGMENTS}

Authors wish to thank Agilent Foundation for the generous technical support. Authors acknowledge financial support of Spanish Ministry of Economy and Competitiveness through CTQ2016-79412-P, and BES-2014-068032 and EEBB-I-1712654 (F.C.C).

\section{REFERENCES}

(1) Toby, T. K.; Fornelli, L.; Kelleher, N. L. Progress in Top-Down Proteomics and the Analysis of Proteoforms. Annu. Rev. Anal. Chem. 2016, 9 (1), 499-519.

Calderón-Celis, F.; Encinar, J. R.; Sanz-Medel, A. Standardization Spectrometry. Mass Spectrom. Rev. 2018, 37 (6), 715-737.

(3) Brett, D.; Pospisil, H.; Valcárcel, J.; Reich, J.; Bork, P. Alternative Splicing and Genome Complexity. Nat. Genet. 2002, 30 (1), 29-30.

Savaryn, J. P.; Catherman, A. D.; Thomas, P. M.; Abecassis, M. M. Kelleher, N. L. The Emergence of Top-down Proteomics in Clinical Research. Genome Med. 2013, 5 (6), 53

Cid-Barrio, L.; Calderón-Celis, F.; Abásolo-Linares, P.; FernándezSánchez, M. L.; Costa-Fernández, J. M.; Encinar, J. R.; Sanz-Medel, A. Advances in Absolute Protein Quantification and Quantitative Protein Mapping Using ICP-MS. TrAC Trends Anal. Chem. 2018, 104, 148-159.

Wang, M.; Feng, W.-Y.; Zhao, Y.-L.; Chai, Z.-F. ICP-MS-Based Strategies for Protein Quantification. Mass Spectrom. Rev. 2010, 29 (2), $326-348$

Wind, M.; Wegener, A.; Eisenmenger, A.; Kellner, R.; Lehmann, W. D Sulfur as the Key Element for Quantitative Protein Analysis by Capillary Liquid Chromatography Coupled to Element Mass Spectrometry. Angew. Chemie Int. Ed. 2003, 42 (29), 3425-3427.

Diez Fernández, S.; Sugishama, N.; Ruiz Encinar, J.; Sanz-Medel, A Triple Quad ICPMS (ICPQQQ) as a New Tool for Absolute Quantitative Proteomics and Phosphoproteomics. Anal. Chem. 2012, 84 (14), 58515857.

(9) Lopez-Ferrer, D.; Hixson, K. K.; Belov, M. E.; Smith, R. D. Ultra-Fast Sample Preparation for High-Throughput Proteomics. In Sample Preparation in Biological Mass Spectrometry; Springer Netherlands: Dordrecht, 2011; pp 125-139.

(10) Calderón-Celis, F.; Diez-Fernández, S.; Costa-Fernández, J. M.; Ruiz Encinar, J.; Calvete, J. J.; Sanz-Medel, A. Elemental Mass Spectrometry for Absolute Intact Protein Quantification without Protein-Specific Standards: Application to Snake Venomics. Anal. Chem. 2016, 88 (19), 9699-9706.

(11) Calderón-Celis, F.; Cid-Barrio, L.; Ruiz Encinar, J.; Sanz-Medel, A.; Calvete, J. J. Absolute Venomics: Absolute Quantification of Intact Venom Proteins through Elemental Mass Spectrometry. J. Proteomics 2017, 164, 33-42.

Wind, M.; Eisenmenger, A.; Lehmann, W. D. Modified Direct Injection High Efficiency Nebulizer with Minimized Dead Volume for the Analysis of Biological Samples by Micro- and Nano-LC-ICP-MS. $J$. Anal. At. Spectrom. 2002, 17 (1), 21-26.

Brun, V.; Masselon, C.; Garin, J.; Dupuis, A. Isotope Dilution Strategies Approaches in Absolute Quantitative Proteomics with Mass

Pereira Navaza, A.; Ruiz Encinar, J.; Carrascal, M.; Abián, J.; SanzMedel, A. Absolute and Site-Specific Quantification of Protein Phosphorylation Using Integrated Elemental and Molecular Mass Spectrometry: Its Potential To Assess Phosphopeptide Enrichment Procedures. Anal. Chem. 2008, 80 (5), 1777-1787.

Liu, R.; Hou, X.; Lv, Y.; McCooeye, M.; Yang, L.; Mester, Z. Absolute Quantification of Peptides by Isotope Dilution Liquid ChromatographyInductively Coupled Plasma Mass Spectrometry and Gas Chromatography/Mass Spectrometry. Anal. Chem. 2013, 85 (8), 4087 4093

(16) Calderón-Celis, F.; Sanz-Medel, A.; Encinar, J. R. Universal Absolute Quantification of Biomolecules Using Element Mass Spectrometry and Generic Standards. Chem. Commun. 2018, 54 (8), 904-907.

Schaumlöffel, D.; Ruiz Encinar, J.; Lobiński, R. Development of a Sheathless Interface between Reversed-Phase Capillary HPLC and ICPMS via a Microflow Total Consumption Nebulizer for Selenopeptide Mapping. Anal. Chem. 2003, 75 (24), 6837-6842.

Delaporte, T. Signal Enhancement of Elements Due to the Presence of Carbon-Containing Compounds in Inductively Coupled Plasma Mass Spectrometry. Anal. Chem. 1991, 63 (14), 1497-1498.

(19) Warburton, E.; Goenaga-Infante, H. Methane Mixed Plasma-improved Sensitivity of Inductively Coupled Plasma Mass Spectrometry Detection for Selenium Speciation Analysis of Wheat-Based Food. J. Anal. At. Spectrom. 2007, 22 (4), 370-376. for Absolute Quantitative Proteomics. J. Proteomics 2009, 72 (5), 740 749.
Kovačevič, M.; Goessler, W. Direct Introduction of Volatile Carbon Compounds into the Spray Chamber of an Inductively Coupled Plasma Mass Spectrometer: Sensitivity Enhancement for Selenium. Spectrochim. Acta Part B At. Spectrosc. 2005, 60 (9-10), 1357-1362.

Zinn, N ; Krüger, R ; Leonhard, P ; Bettmer, J. MLC Coupled to ICPSFMS with Post-Column Isotope Dilution Analysis of Sulfur for Absolute Protein Quantification. Anal. Bioanal. Chem. 2008, 391 (2), $537-543$

Wang, M.; Feng, W.; Lu, W.; Li, B.; Wang, B.; Zhu, M.; Wang, Y.; Yuan, H.; Zhao, Y.; Chai, Z. Quantitative Analysis of Proteins via Sulfur Determination by HPLC Coupled to Isotope Dilution ICPMS with a Hexapole Collision Cell. Anal. Chem. 2007, 79 (23), 9128-9134.

Pröfrock, D.; Prange, A. Compensation of Gradient Related Effects When Using Capillary Liquid Chromatography and Inductively Coupled Plasma Mass Spectrometry for the Absolute Quantification of Phosphorylated Peptides. J. Chromatogr. A 2009, 1216 (39), 6706-6715.

Humphrey, S. J.; James, D. E.; Mann, M. Protein Phosphorylation: A Major Switch Mechanism for Metabolic Regulation. Trends Endocrinol. Metab. 2015, 26 (12), 676-687.

Cohen, P. The Origins of Protein Phosphorylation. Nat. Cell Biol. 2002, 4 (5), E127-E130.

Newman, R. H.; Zhang, J.; Zhu, H. Toward a Systems-Level View of Dynamic Phosphorylation Networks. Front. Genet. 2014, 5, 263.

Yan, J. X.; Packer, N. H.; Gooley, A. A.; Williams, K. L. Protein Phosphorylation: Technologies for the Identification of Phosphoamino Acids. J. Chromatogr. A 1998, 808 (1-2), 23-41.

Boehm, M. E.; Seidler, J.; Hahn, B.; Lehmann, W. D. Site-Specific Degree of Phosphorylation in Proteins Measured by Liquid Chromatography-Electrospray Mass Spectrometry. Proteomics 2012, 12 (13), 2167-2178.

Tsai, C.-F.; Wang, Y.-T.; Yen, H.-Y.; Tsou, C.-C.; Ku, W.-C.; Lin, P.-Y.; Chen, H.-Y.; Nesvizhskii, A. I.; Ishihama, Y.; Chen, Y.-J. Large-Scale Determination of Absolute Phosphorylation Stoichiometries in Human Cells by Motif-Targeting Quantitative Proteomics. Nat. Commun. 2015, 6,6622 .

J.-C. Phosphorylation of Caseins, Present Evidence for an Amino Acid Triplet Code Posttranslationally Recognized by Specific Kinases. Biochimie 1981, 63 (1), 1-17.

Wind, M.; Wesch, H.; Lehmann, W. D. Protein Phosphorylation Degree Determination by Capillary Liquid Chromatography and Inductively Coupled Plasma Mass Spectrometry. Anal. Chem. 2001, 73 (13), 30063010 .

Pereira Navaza, A.; Ruiz Encinar, J.; Sanz-Medel, A. Absolute and Accurate Quantification of Protein Phosphorylation by Using an Elemental Phosphorus Standard and Element Mass Spectrometry. Angew. Chemie Int. Ed. 2007, 46 (4), 569-571.

Millioni, R.; Tolin, S.; Puricelli, L.; Sbrignadello, S.; Fadini, G. P.; 
Tessari, P.; Arrigoni, G. High Abundance Proteins Depletion vs Low Abundance Proteins Enrichment: Comparison of Methods to Reduce the Plasma Proteome Complexity. PLoS One 2011, 6 (5), e19603.

(34) Labunskyy, V. M.; Hatfield, D. L.; Gladyshev, V. N. Selenoproteins: Molecular Pathways and Physiological Roles. Physiol. Rev. 2014, 94 (3), 739-777.
(35) Salvatore, G.; Edelhoch, H. Chemistry and Biosynthesis of Thyroid Iodoproteins. In Hormonal Proteins and Peptides; Li, C. H., Ed. Elsevier: London, 2014; pp 201-234.

(36) Shen, S.; Li, X.-F.; Cullen, W. R.; Weinfeld, M.; Le, X. C. Arsenic Binding to Proteins. Chem. Rev. 2013, 113 (10), 7769-7792.

\section{Insert Table of Contents artwork here}

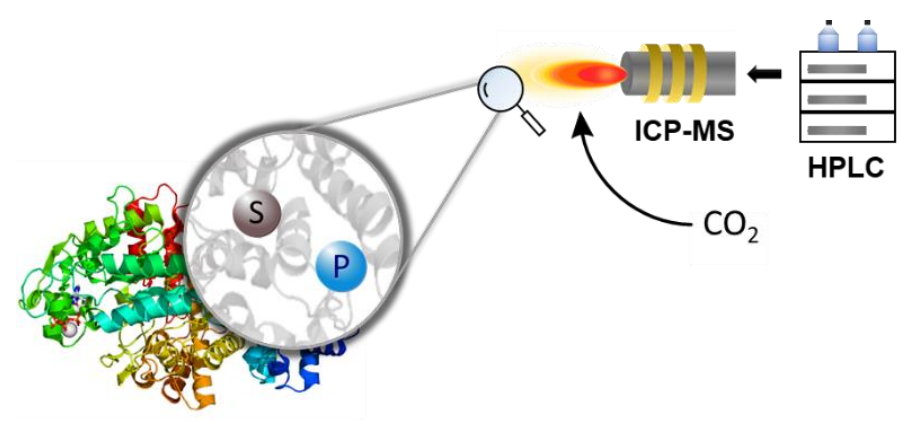

Keywords: Proteomics, Protein Quantification, Post-translational modifications, ICP-MS/MS, Phosphorylation 